\title{
Exploration of Official We-chat Business Practice of University Library Manifestation
}

\author{
Zhiyuan Zhao \\ Library of Baicheng Normal University, Jilin Province, China
}

ZhiyuanZhao@163.com

Keywords: University; Library; We-chat; Official management

\begin{abstract}
With the continuous development of social economy, incessant progress of electronic information technology as well as the popularization of the Internet, We-chat has been widely applied in information service of university libraries gradually. Universities take advantage of Wechat to operate libraries. In this way, it can change the traditional publicity ways and has great publicity effects; in the meantime, utilizing We-chat can realize functions such as holding inquiry and renewal of books, thereby improving service quality of books; besides, utilizing We-chat can realize close communication with users and shorten the distance between the two parties; lastly, utilizing We-chat for prize quiz and other activities can strengthen communication and cooperation of both parties. This paper first introduces the concept and characteristics of We-chat as well as the current situation of university library official We-chat; then, it discusses the application of We-chat in libraries, hoping to provide some references for university libraries official We-chat.

Process of advanced scientific technology and the endless emergence of various information spreading ways make users' using habits change gradually. Libraries have been paying attention to communication with users, so no matter it is Micro-blog or QQ online consultation, they are all communication ways that libraries use. From 2011 when Tencent Company issued We-chat, Wechat has become an inseparable part of people's daily life. People use We-chat to renew Circle of Friends and daily voice communication and so on. The continuous development of We-chat also make lots of libraries interested, so numerous libraries have established their own official We-chat. However, the operating conditions of current Chinese libraries are still in initial stage. To make the operation of We-chat satisfy users' various demands, it still needs endless exploration of university libraries. Firstly, let us have a look at the application conditions of We-chat in university libraries.
\end{abstract}

\section{Application status of We-chat in university libraries}

We-chat is a kind of chatting software that Tencent Company issued in 2011 for smartphone communication service. Users can send texts, voices, videos and pictures through cellphones or websites; in the meantime, We-chat also provides functions such as public platform, Circle of Friends and scanning so that users can pay attention to public accounts, add friends and establish We-chat group by scanning numbers or two-dimensional code [1]. As a new information communication platform, We-chat can provide better service to reader if utilized appropriately in libraries. Because of the rapid development of mobile Internet technology, various mobile application technologies also have corresponding development. It enriches and changes people's life. In order to grasp the utilization status of We-chat in domestic university libraries, the author searched on CNKI and We-chat with the index words of "library" and "We-chat", and there are altogether 243 items of results. That is to say, there are about over 200 libraries in China that have their own We-chat public platform. However, if we take a careful look at it, the implementation degrees of We-chat in various university libraries are somewhat different. Some universities have opened up official university libraries, but have not had interaction with users. Some universities have established subscription account and service account, while some universities have not. The author also investigated libraries that have established We-chat public platform and found that most of the domestic libraries would formulate and issue We-chat articles such as "pictures and books", "recommendation of new books" as well as "extracurricular" at regular intervals; some libraries even take advantage of We-chat to issue hot topics of the library regularly, such as recommendation 
of newly-purchased books, readers' voices and so on. [2] At the same time, the author also finds that the fixed module of domestic libraries is mainly used for searching for common information, library collection and individual lending and so on. With the application of We-chat in university libraries, the number of We-chat users in Chinese university libraries is rising continuously. Through investigations, the author finds that generally speaking, the present management situation of universities' We-chat is still in initial stage and it still needs incessant exploration in later practices so as to improve their own We-chat management standard.

\section{Management of university libraries' official We-chat}

According to historical information of We-chat, the library that provides earliest We-chat service is Beijing International Studies University library, which began to use We-chat to provide information service to users. With the continuous development of We-chat, a lot of university libraries have established We-chat public platform up to the present. However, from the establishment process of We-chat public platform, we can find that development of Chinese Wechat libraries is still in the initial stage. Combining the management situation of Chinese university libraries, the author proposes his own opinions about We-chat operation in university libraries from the following aspects:

Allowing readers to understand library services. The purpose of library is to provide reading services. In real life, libraries have adopted various service means for readers to read conveniently and achieve relative materials. For example, document delivery, inter-lending and so on. However, readers' feedback to these services did not conform to expectations. That is to say, users' do not have high opinions for libraries. In the meantime, this is also one of the major problems that disturb librarians. However, during investigation, the author finds that another reason for the low opinion is that a lot of readers do not know libraries have such kind of service. In March 2015, the author conducted questionnaires to 1500 students in Xi' an University of Finance and Economics, asking if students know that their library has the service of "recommendation of books". Among students under investigation, $62.3 \%$ of students do not know this service and only $37.7 \%$ of students know it. Among students who do not know this service, 95\% of students expressed that they were willing to use this service. If university libraries want to have good service effects, it is critical that readers know this service item. About this point, the author believes that university libraries can publicize from the following two aspects:

(1) Utilizing traditional posters for active entity publicity. In new media environment, publicity of libraries usually needs to rely on network and other channels. During investigation of library in Xi'an University of Finance and Economics, the author finds that the university usually utilizes Campus Network, We-chat and emails to push information of the library to teachers and students. While during investigation of users, when they were asked how they obtained library information, about $55 \%$ of users believed that they saw the information from the posters in front of the library gate. Therefore, we can see that information publicity by means of traditional posters might be an appropriate publicity way. With the gradual upgrading of We-chat, university libraries can design large-scale posters and put them at the library gate and set multiple two-dimensional codes with several types at the gate of the reading room, which might be convenient for users to pay attention to W-chat information anytime anywhere.

(2) Encouraging readers to pass share the information and bilateral interaction, increasing publicity of the library. It is not enough to rely on publicity of library. University libraries can take advantage of We-chat platform, organize and plan award activities about sharing information to increase publicity of the library. For example, Xi'an Eurasia University planed a lottery activity that encouraged sharing information during the 2015 "Reading Festival". The activity lasted for a week, and the rules were: anyone introducing 3 friends to pay attention to the library's official Web-site could participate in lottery and the list of 10 prizewinners would be published every day, and there were corresponding prizes. During the activity, the library published 7 pieces of information altogether, and about 1000 people read the information. When this activity finished, the number of 
people who paid attention to the library rose to about 2000. Therefore, we can see that sharing the information is a feasible way of publicity.

Valuing functional principle. It is the first step to adopt various means to have users pay attention to We-chat, while the key to We-chat operation is keeping users. During the operational process, We-chat should pay attention to functional principle. To users of university libraries, the most obvious convenience of paying attention to library We-chat is inquiry of library collection and knowing one's own borrowing condition [3].

(1) Using We-chat to search for library information. University libraries can implement specific We-chat inquiry by taking advantage of We-chat platform besides sending information. The appearance of We-chat has changed people's past living habits. Most importantly, it changes Chinese people's past living habits and various traditional communication ways are neglected. It breaks traditional communication ways and makes information fair, open and impartial, strengthens intimacy among people and makes information asymmetry receive efficient balance. We-chat is changing people's all life styles with gigantic subversive power, and management of university libraries is no exception. Management of their official We-chat includes many items, such as book inquiry, borrowing, inquiry, renewal of books and so on, thereby providing services to readers. At present, a lot of university libraries in China have opened up the function of book inquiry. For example, We-chat of Shaanxi Normal University library. As long as one starts the function of searching and inputs the name of the book he is about to look up, relative information about the book would be presented on the website clearly, which is convenient for readers to use.

(2) Providing information consultation service. We-chat public platform can also provide online consultation function to readers. When readers meet difficulty, they can send help information through the platform. When librarians receive the request, they could answer the question in simple words and readers can receive help through We-chat. In the meantime, university libraries can also understand users' real thoughts through We-chat and improve problems during the operation of libraries incessantly and improve the information service quality of libraries.

Effects of affinity. We-chat public platform has the function of sending information to all users and the combination of words and pictures is the unique form of message that We-chat has and is also the most popular form among users. At present, the number of We-chat users is still increasing. The popularity of picture-text information can be represented in the reading quantity of it. During the investigation process of Northwest University library, which has operated over a year, the author finds that the library has sent altogether 95 group messages to user group and about 6 of them are about lecture notices with 5\% of reading amount, book resources are 45 pieces with $8 \%$ of reading amount, library notices are 4 with $15 \%$ of reading amount, lottery-attached interaction are 20 with 19\% of reading amount, and affinity posts are 3 with $53 \%$ of reading quantity [4]. These 3 affinity posts are freshmen publicity, student from Northwest University going on The Voice of China and Northwest University library opening up Tai'an database. Especially the affinity post of the student on The Voice of China, which is attached with the most popular music elements at present, the page view reached over tens of thousands on that day. Therefore, we can see that affinity post has huge influences on readers. University libraries should choose language expression ways that are close to users and draw close the distance between the library and users so that more users will have a good impression on university libraries and further improve their good reputation to the library.

Adopting lottery-attached incentive mechanism. During investigation of Northwest University library, the author finds that besides affinity post that has high page view, another popular one is lottery-attached information, which is quite general in the operational process of daily public platform. Though the major responsibility of a library is to communicate culture, adopting appropriate incentive mechanism and exploring users' likes and applying business marketing ways for publicity are also important ways. [5] For example, there are two database lectures about life science; if one is a We-chat notice issued by general officials, while the other is a lottery-attached lecture, then obviously, reading quantity of the lottery-attached lecture would rise instantly; before the beginning of the lecture, more students would come and listen to the lecture. Therefore, it is 
obvious that lottery-attached incentive mechanism is beneficial to attracting more students to participate in the lecture and is of great importance to improve students' educational level and improve the teaching quality of universities.

\section{Conclusion}

During the operational process of university libraries, functional principle should be observed and users should know the service content; also, libraries should take advantage of affinity means, strengthen relation with users, adopt lottery-attached incentive mechanism, improve the library's popularity and reputation and change the library's official image continuously; in the meantime, they should strengthen interactions with users, find and correct problem in time and provide better services to readers. Today, when social economy is developing continuously, university libraries should abide by the principle of serving for readers, innovate their own management mode incessantly, improve technological means and use new technology to serve for users remorselessly so that they will be loved by users and their reputation will be raised.

\section{References}

[1] Shi Mei, Zhai Xiaojuan. A Research of University Library Official We-chat Management Strategy_-Taking Nanjing University Library as an Example. University Library Journal, 2014,32(5):79-85,116

[2] Ma Dayan, Li Xuejing, Chen Hongjing. Analysis of Current Status of University Library Wechat Service and Development Strategies__Based on Researches of "985 Project" University Libraries. Library Work and Research, 2015,(3):33-37.

[3] Wang Yong, Hong Bin. We-chat and Its Application in Libraries.New Century Library,2013,(9):45-49.

[4] Zhao Chuang, Wang Daizun. Library Application Based on "We-chat" and Its Servce Mode. Modern Intelligence, 2014,34(11):104-106,155.

[5] Wei Xiaoxiao. A Research Based on University Library Mobile Information Service of "Wechat”. Information Technology, 2015,(5):106-109,113. 